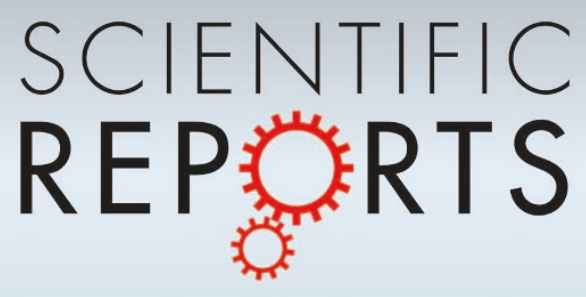

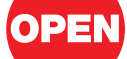

SUBJECT AREAS:

CONSERVATION

ENVIRONMENTAL MONITORING

RISK FACTORS

ICHTHYOLOGY

Received

13 March 2012

Accepted

5 April 2013

Published

29 April 2013

Correspondence and requests for materials should be addressed to

T.M. (ecofish77@ yahoo.co.jp)
Overview of active cesium contamination of freshwater fish in Fukushima and

\section{Eastern Japan}

\author{
Toshiaki Mizuno \& Hideya Kubo
}

The Center for Risk Research, Shiga University.

This paper focuses on an overview of radioactive cesium 137 (quasi-Cs137 included Cs134) contamination of freshwater fish in Fukushima and eastern Japan based on the data published by the Fisheries Agency of the Japanese Government in 2011. In the area north and west of the Fukushima Nuclear plant, freshwater fish have been highly contaminated. For example, the mean of active cesium (quasi-Cs137) contamination of Ayu (Plecoglossus altivelis) is 2,657 Bq/kg at Mano River, $20-40 \mathrm{~km}$ north-west from the plant.

Bioaccumulation is observed in the Agano river basin in Aizu sub-region, 70-150 km west from the plant. The active cesium (quasi-Cs137) contamination of carnivorous Salmondae is around 2 times higher than herbivorous Ayu. The extent of active cesium (quasi-Cs137) contamination of Ayu is observed in the entire eastern Japan. The some level of the contamination is recognized even in Shizuoka prefecture, $400 \mathrm{~km}$ south-west from the plant.

Tat

he serious accidents of the Fukushima Nuclear Power Plant have been contaminating a vast area in eastern $J^{J a p a n}{ }^{1}$, home of 60 million people. Consumption of freshwater fish is an important part of the aquatic pathway for the transfer of radionuclides to the freshwater ecosystem creatures including humans ${ }^{2}$. Therefore the contamination of freshwater fish of aquatic bioaccumulation is an important problem ${ }^{3,4}$. In the case of the Chernobyl Accident, the transfer of radionuclides to fish has been studied in European countries ${ }^{5-7}$. Most attention was focused on Belarus, the Russian Federation and Ukraine, because of the higher contamination of water bodies in these areas ${ }^{8,9}$. However, in the case of Fukushima, there is little information about freshwater ecosystem contamination in 2011. Therefore, this paper focuses on an overview of active cesium 137 (quasiCs137) contaminations of freshwater fish in Fukushima and eastern Japan based on 2011 data published by the Fisheries Agency of the Japanese Government ${ }^{10}$.

\section{Results}

Highest contaminated area in fukushima prefecture. Fukushima Prefecture is located in the northeastern part of the Main Island of Japan (Fig. 1). It is divided into three sub-regions by its mountainous topography, i.e., Hamadori, Nakadori and Aizu (from east to west). Hamadori is the coastal region facing the Pacific Ocean and separated from Nakadori (central basin) by the Abukuma Highlands. The westernmost Aizu is mountainous with the Aizu Basin in the center. There still is a rich natural environment maintained throughout the prefecture with three national parks, one quasi-national park and eleven prefectural parks present. The mountain ranges form headwaters and basins of many rivers such as the Abukuma River and the Aga River. The Abukuma Highlands is designated as one of the prefectural parks and rich in endemic wildlife including the indigenous forest green tree frog (Rhacophorus arboreus) and salamanders (Hynobius lichenatus, Hynobius nigrescens). There the Ayu (Plecoglossidae: Plecoglossus altivelis altivelis), Salmon (Salmonidae: Oncorhynchus masou, Salvelinus leucomaenis) and carp (Cyprinidae: Tribolodon hakonensis, Cyprinus carpio, Carassius.sp) are very popular freshwater fish for fishing and angling.

The Fukushima Nuclear Power Plant is located in Hamadori. Due to the topography with the Pacific Ocean in the east and the Abukuma Highlands in the west, the areas in the north to the west of the plant are highly contaminated. Such areas include Iidate Village and Date City. The Mano River which flows through Iidate Village in the upstream and Minami-souma City. Two months after the accident, the Ministry of Land, Infrastructure and Transport surveyed the Mano River ${ }^{11}$. The survey results of the contamination level of the bottom soil are Cs134: 6,900 Bq/ $\mathrm{kg}$ and Cs137: 7,800 Bq/kg in Mano River of Minamisouma city at Majima bridge on 29/5/2011. While the area downstream and the Abukuma River in Date City found higher 


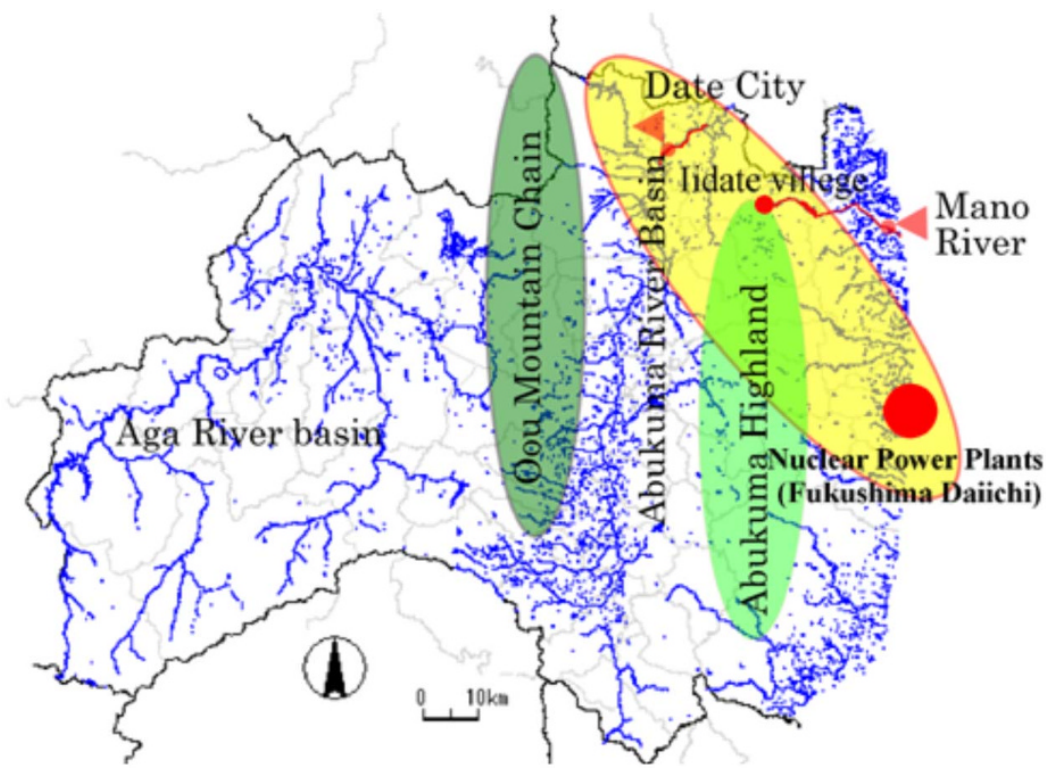

Figure 1 Fukushima prefecture water system. Blue is water system: Aga river basin is west area of Fukushima, Abkuma river basin is center of Fukushima. Green is mountain chain or highland where heights is more 1,000 m. Yellow is high contaminated area by nuclear accidents. We created the map using the GIS software which is 'MANDARA for windows 2000/XP/VISTA/7 Version 9.35' (the software copyright: 1992-2011 Tani Kenji).

contamination. Two months after the accident, the Ministry of Environment surveyed the Abukuma River of Date city. The survey results of the contamination level of the bottom soil are Cs134: 11,000 Bq/kg and Cs137: 12,000 Bq/kg in Abukuma River of Date city at Taisho bridge on 24/5/2011.

The contamination level of radioactive cesium (quasi-Cs137) of the Ayu, annual and herbivorous species, captured in these rivers or their tributaries between May and September 2011 was measured. The cesium bioaccumulation of those captured in the Mano River was mean 2,657 Bq/kg ( $=3$, median 2,900 Bq/kg, range 1,770$3,300 \mathrm{~Bq} / \mathrm{kg}$ ) and the Abukuma River at Date city was mean $1,770 \mathrm{~Bq} / \mathrm{kg}$, ( $\mathrm{n}=11$, median $1,170 \mathrm{~Bq} / \mathrm{kg}$, range 650-2,080 Bq/kg).

The bioaccumulations of Aga river basin (West Fukushima). The Aga River Basin encompasses the entire Aizu region in west Fukushima. The river water flows through from the Aizu region to the Sea of Japan. As it lies over $70 \mathrm{~km}$ to the west of the nuclear power plant and both the Abukuma Highlands and Oou montain chain are in between, the Cs137 contamination level here was lower than Mano river and the Abukuma river basin. Two months after the accident, Fukushima prefecture surveyed the Agano River (Aga river Basin) of Aizu and South Aizu region ${ }^{12}$. The survey results of the contamination level of bottom soil were Cs134: $29 \mathrm{~Bq} / \mathrm{kg}$ and Cs137: $33 \mathrm{~Bq} / \mathrm{kg}$ in Agano River of Aizu region at Miyako bridge on 27/5/2011, Cs134: $29 \mathrm{~Bq} / \mathrm{kg}$ and Cs137: $34 \mathrm{~Bq} / \mathrm{kg}$ in Agano river of Minami-Aizu region at Tajima bridge on 27/5/2011.

In the aga river basin, the bioaccumulation of fish are well recognized. Fig. 2 shows the quasi-Cs137 contamination and bioaccumulation levels of three fish families captured in the basin, i.e., Plecoglossidae (Plecoglossus altivelis $\mathrm{n}=18$ ), Cyprinidae (Tribolodon hakonensis $\mathrm{n}=25$, Cyprinus carpio $\mathrm{n}=5$, Carassius sp. $\mathrm{n}=11$ )and Salmonidae(Oncorhynchus masou $\mathrm{n}=12$, Salvelinus leucomaenis $\mathrm{n}=13$ ) between April and December 2011. Since p-value $=0.008$ $\leq 0.05$ of Kruskal-Wallis Test, at the $\mathrm{p}=0.05$ level of significance, there exists enough evidence to conclude that there is a difference among the three families based on the active cesium contamination level. The median of herbivorous Plecoglossidae shows the lowest level among the three families $(\mathrm{n}=18$, mean $50.64 \mathrm{~Bq} / \mathrm{kg}$, median $=46.00 \mathrm{~Bq} / \mathrm{kg}$, range $12.00-90.00 \mathrm{~Bq} / \mathrm{kg}$ ). Then the median of omnivorous Cyprinidae shows about 1.6 times $(\mathrm{n}=41$, mean
$79.80 \mathrm{~Bq} / \mathrm{kg}$, median $72.00 \mathrm{~Bq} / \mathrm{kg}$, range $15.00-210.00 \mathrm{~Bq} / \mathrm{kg}$ ) and the mean of carnivorous Salmonidae about 1.9 times higher $(\mathrm{n}=25$, mean $96.24 \mathrm{~Bq} / \mathrm{kg}$, median $89.00 \mathrm{~Bq} / \mathrm{kg}, 17-200 \mathrm{~Bq} / \mathrm{kg}$ ) than Plecoglossidae.

The widespread contamination in eastern Japan. To the south west of Fukushima prefecture, there lies the Kanto region which as well as containing the metropolitan prefecture of Tokyo also comprises Ibaraki prefecture, Tochigi prefecture, Gunma prefecture, Saitama prefecture, and Chiba prefecture. In the area, there is the Tone river basin that is the one of biggest river basins $\left(16,840 \mathrm{~km}^{2}\right)$ in Japan. Therefore, there are not only many source points of water springs and many rivers and streams but also high density water network systems of irrigation canals and urban water systems. Freshwater fish inhabit all types of water systems. As a result, the level of freshwater

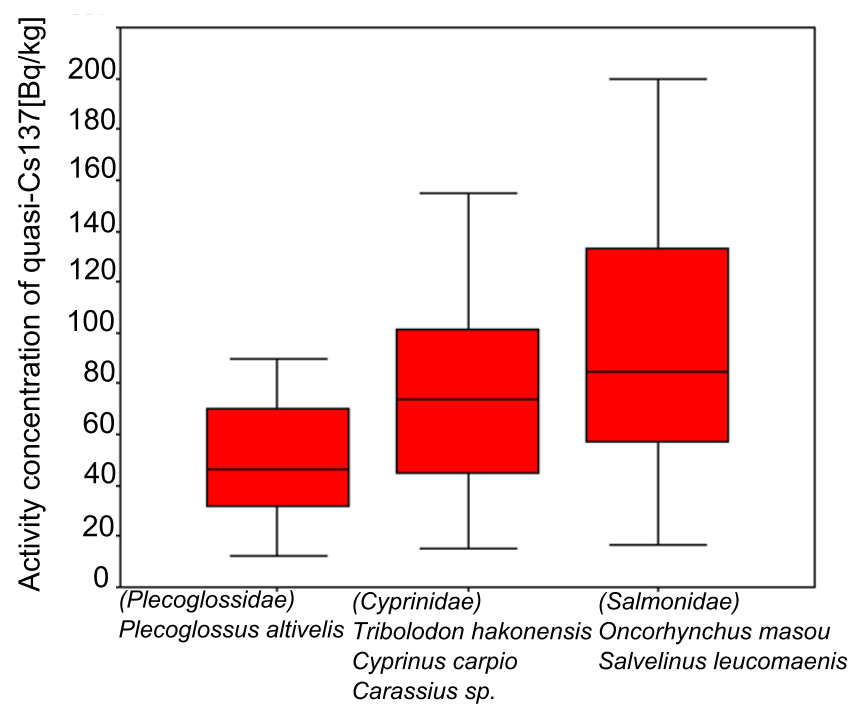

Figure 2 Error bars indicate ranges of concentration of active cesium (quasi-Cs137) each family on Aga river basin. The box plots indicate inter-quartile ranges of these data. Bars are into the each box indicate the each median. 
contamination can be taken as an index of the environmental contamination of the freshwater ecosystem. The isogram map (Fig. 3) shows an average of quasi-Cs137 for each prefecture about contamination levels of the Ayu (Plecoglossus) captured in between May and September 2011.

The relation between distance from power plant and contamination level. We found a relation between the distance from the power plant and the quasi-Cs137 contamination level of freshwater fish. According to the result of inverse regression analysis about quasi-Cs137 contamination levels related to the distance from the nuclear power plants of each prefectural capital city, the equation is: $\mathrm{Y}=27339.82^{-1} \times-75.13(\mathrm{Y}=$ Cesium, $\mathrm{X}=$ The Distance from the plants to each prefecture's capital city, Signif $\mathrm{F}=0.009<$ 0.05 , Adjusted R Square 0.50). In areas within a radius of $100 \mathrm{~km}$ from the nuclear plant, active cesium contamination levels of the Ayu are more than $200 \mathrm{~Bq} / \mathrm{kg}$. In those between a radius of $100 \mathrm{~km}$ and $200 \mathrm{~km}$, it is around $60-200 \mathrm{~Bq} / \mathrm{kg}$. In those between a radius of $200 \mathrm{~km}$ and $300 \mathrm{~km}$ in which Tokyo is included, it is $20-60 \mathrm{~Bq} / \mathrm{kg}$. Therefore, it is estimated that contamination of freshwater fish is extended to all prefectures in eastern Japan. The contamination is recognized as far as Shizuoka prefecture, $400 \mathrm{~km}$ south-west from the plant.

\section{Discussion}

The Japanese freshwater system is very high density as developed rice water paddy field, irrigation canal, urban water-system network. Therefore, we have to think that the contamination of freshwater fish is widespread not only in river basins but also all over the ground included all types of water-systems, for example, agricultural and urban water systems. The isogram map shows the contamination tendency quite well. The contamination levels of the freshwater fish provide insufficient data and the knowledge of the path about bioaccumulation. So, we will have to survey a more wide spread area and monitor bioaccumulation in each species level.

In this paper we show the relation between distance and contamination levels by inverse regression analysis. The results indicate the

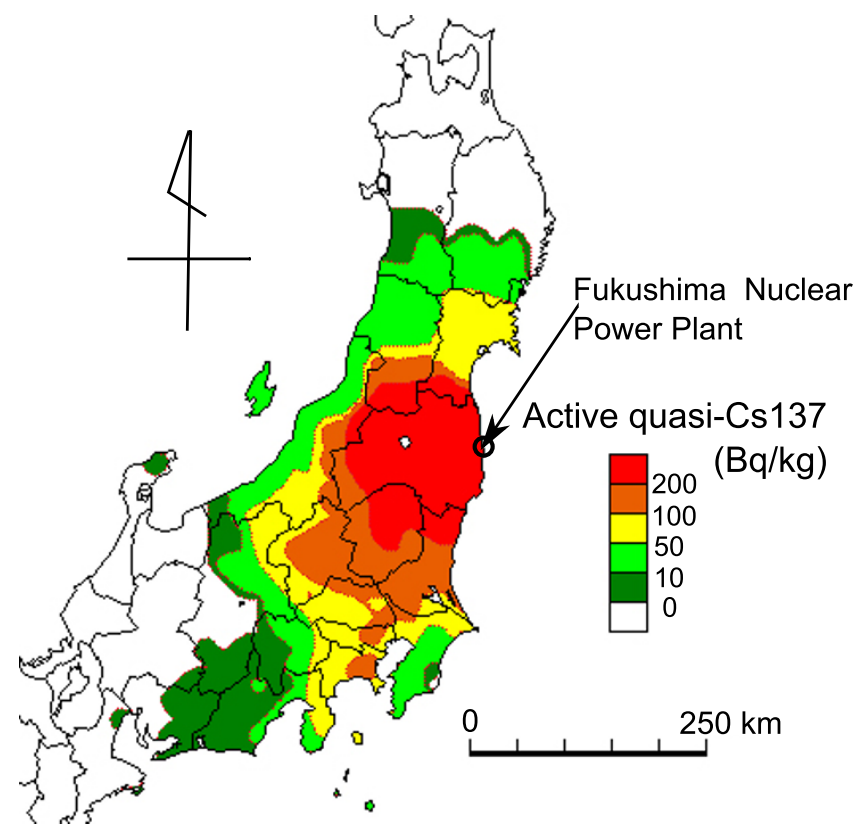

Figure 3 The isogram map shows average active cesium (quasi-Cs137) contamination level of the Ayu (Plecoglossus) captured in between May and September 2011 on each prefectures in eastern Japan. Each isogram center points are each prefecture's capital city. We created the map using the GIS software which is 'MANDARA for windows 2000/XP/VISTA/7 Version 9.35' (the software copyright: 1992-2011 Tani Kenji). effects of quasi radioactive cesium 137 by the Fukushima accident look like less serious than those of the Chernobyl accident. However, contamination levels are possibly higher than the Chernobyl as the cesium is concentrated by the water systems in limitation region. Water paddy field look like shallow pond saved mud included cesium 137. Moreover, the cesium 137 will distribute and concentrate by high density irrigation canal and urban water-system. For example, the highly contaminated Taisho river bottom soil Cs134: 4,335 Bq/kg, Cs137: 5,456 Bq/kg was found at 1/11/2011 at Kitakashiwa bridge of Kashiwa city in Tokyo metropolitan area, $200 \mathrm{~km}$ south-west from the plant ${ }^{13}$. Therefore we must carefully and continuously monitor the contamination to the freshwater ecosystem and human health.

\section{Methods}

Data 2011 of radioactive cesium of freshwater fish was analyzed by each local government according to the emergency food survey manual of radioactive substance ${ }^{14}$ The purpose of this manual is they avoid feeding high contaminated food it was defined by food security of emergency condition. Therefore, it is not aimed at collecting accurate data. As a result, this data did not distinguish between cesium 137 and cesium 134. Therefore, the analysis of this paper calculated by quasi-Cs137 included Cs134. They used germanium semiconductor machine when they measured the radioactive cesium contamination of freshwater fish. The measure time is from 10 minute to 1 hour. The calibration is only Cs137 in per week. The range of radioactive cesium applied only Cs137 regression equation. The result, when the case included Cs134 is relatively much, the numerical value become over estimation. The sample of freshwater fish was collected by each prefectural government by emergency policy of food security. In the survey, the fish sample collected 5-10 $\mathrm{kg}$ in one survey station. The measure is using wet condition fish. Ayu and small fish was measured hole body, while big fish measured the part of food portion.

1. Monitoring information of environmental radioactivity level, MEXT and DOE Airborne Monitoring, Ministry of Education, Culture, Sports, Science \& Technology in Japan, http://radioactivity.mext.go.jp/en/list/203/list-1.html (2013).

2. Joanna, B. et al. Radiocesium in Fish from the Savannah River and Steel Creek: Potential Food Chain Exposure to the Public. Risk Analysis Vol. 21, No.3, 545-559 (2001).

3. McCreedy, C. D., Jagoe, C. H., Glickman, L. T. \& Brisbin Jr, I. L. Bioaccumulation of cesium-137 in yellow bullhead catfish (Ameiurus natalis) in habiting an abandoned nuclear reactor reservoir. Environmental Toxicology and Chemistry 16, 328-335 (1997)

4. Rowan, J. R. \& Rasmussen, J. B. Bioaccumulation of radiocesium by fish: The influence of physicochemical factors and trophic structure. Canadian Journal of Fisheries and Aquatic Science 51, 2388-2410 (1994).

5. Hakanson, L., Anderson, T. \& Nilsson, A. Caesium-137 in perch in Swedish lakes after Chernobyl-present situation, relationships and trends. Environmental Pollution 58, 195-212 (1989).

6. Ugedal, O., Forseth, T., Jonsson, B. \& Njastad, O. Sources of variation in radiocesium levels between individual fish from a Chernobyl contaminated Norwegian lake. Journal of Applied Ecology 32, 352-361 (1995).

7. Elliott, J. M. et al. Sources of variation in post-Chernobyl radiocesium in fish from two Cumbrian lakes (north-west England). Journal of Applied Ecology 29, 108-119 (1992)

8. Long-Term Observation of Radioactivity Contamination in Fish around Chernobyl. RYABOV I N Vol 79, 112-122 (2002).

9. Environmental consequences of the Chernobyl accident and their remediation : twenty years of experience report of the Chernobyl Forum Expert Group 'Environment'. Vienna: International Atomic Energy Agency (2006).

10. Results of the inspection on radioactivity materials in fisheries products, Fisheries Agency, http://www.jfa.maff.go.jp/e/inspection/index.html (2012).

11. Urgent radionuclides monitoring report in public water system area of Fukushima prefecture (in Japanese), Ministry of Environment, http://www.env.go.jp/water/ suiiki/urgent/result201106.pdf (2011).

12. Urgent environmental radionuclides monitoring report in public water system area of Fukushima prefecture at 4/6/2011(in Japanese), Fukushima Prefecture, http://www.pref.fukushima.jp/j/koukyouyousuiikimonitaring.pdf (2011).

13. Final report of the highly contamination spot in Kashiwa city (in Japanese), Ministry of Environment, http://www.env.go.jp/press/press.php?serial=14647 (2012).

14. The survey manual "Guide: Emergency Preparedness for Nuclear Facilities", Nuclear Safety Commission, June, 1980-final revised in 2010 (2010).

\section{Acknowledgments}

This paper was as part of the water risk research project at Center of Risk Research of Shiga University. Thankful that Mr. Shigeki Komori (WWF Japan) advised us for improvement of this paper. 


\section{Author contributions}

T.M. wrote the main manuscript text and prepared figures. All authors reviewed the manuscript.

\section{Additional information}

Competing financial interests: The authors declare no competing financial interests.

License: This work is licensed under a Creative Commons

Attribution-NonCommercial-NoDerivs 3.0 Unported License. To view a copy of this

license, visit http://creativecommons.org/licenses/by-nc-nd/3.0/
How to cite this article: Mizuno, T. \& Kubo, H. Overview of active cesium contamination of freshwater fish in Fukushima and Eastern Japan. Sci. Rep. 3, 1742; DOI:10.1038/srep01742 (2013). 